\title{
Perinatal Changes in Lung Surfactant Calcium Measured In Situ
}

\author{
R. G. Eckenhoff \\ Department of Anesthesia and Institute for Environmental Medicine, University of Pennsylvania \\ Medical School, Philadelphia, Pennsylvania 19104
}

\begin{abstract}
Calcium ion is thought to play a role in the structure and function of pulmonary surfactant after secretion into the alveolar space. Since fetal lung liquid calcium concentration is inadequate for this hypothesized role, at a time when optimal surfactant function is necessary for survival, we speculated that the necessary calcium is secreted with the surfactant material, i.e., in the lamellar body. Lungs from rat fetuses at 20,21 , and $22 \mathrm{~d}$ gestation, and also from newborn rats at 3-5 h, 1 and $3 \mathrm{~d}$, were rapidly frozen, sectioned, freeze-dried, and examined cold $\left(-100^{\circ} \mathrm{C}\right)$ in a transmission electron microscope equipped with a fully quantitative energy-dispersive $x$-ray detector and analyzer. X-ray spectra were collected from the lamellar bodies and cytoplasm of type II cells at each time point. Lamellar body calcium concentration in the fetus was approximately twice that of the adult $(70 \pm 4$ vs. $37 \pm 2 \mathrm{mmol} / \mathrm{kg}$ dry wt $\pm S E M$, $P<0.01$ ), and it decreased rapidly after birth to adult levels. Apically located lamellar bodies in the fetus have a signifcantly higher calcium concentration than those in a perinuclear position $(76 \pm 4$ vs. $52 \pm 3, P<0.01)$. There is a significant correlation of calcium and chloride concentrations in lamellar bodies, suggesting that factors responsible for the distribution of chloride, i.e., pH, may also be responsible for the accumulation of calcium by these organelles. These results show that mature calcium transport in lamellar bodies is achieved prenatally in the rat, and suggest that the calcium required for normal surfactant function at birth is secreted with the lamellar body.
\end{abstract}

\section{Introduction}

Pulmonary surfactant is a complex material made and secreted by the alveolar type II epithelial cells (1). The primary function of surfactant is to reduce and regulate surface tension in the alveolus, which decreases the work of breathing and prevents lung collapse at low lung volumes. Deficiency or dysfunction of surfactant results in severe lung disease, the best example of which is respiratory distress syndrome (RDS) ${ }^{1}$ of

Address reprint requests to Dr. Eckenhoff, Institute for Environmental Medicine, University of Pennsylvania Medical School, 1 John Morgan Building, Philadelphia, PA 19104-6068.

Received for publication 5 January 1989 and in revised form 10 May 1989.

1. Abbreviations used in this paper: EPMA, electron probe microanalysis; ER, endoplasmic reticulum; RDS, respiratory distress syndrome; SP-A, surfactant-associated proteins; TM, tubular myelin.

J. Clin. Invest.

(c) The American Society for Clinical Investigation, Inc. 0021-9738/89/10/1295/07 \$2.00

Volume 84, October 1989, 1295-1301 the premature newborn, in which an absolute deficiency of surfactant material exists due to immaturity of the type II cells (2). Other surfactant deficiency or dysfunction states are being increasingly recognized $(3,4)$.

Calcium ion has been found to be of importance in surfactant physiology, not only as an intracellular second messenger in stimulated secretion (5), but also in the extracellular structure and function of surfactant material. For example, surfactant material is stored in secretory granules known as lamellar bodies, which, when exocytosed into the alveolar lumen, undergo a transformation from the multilamellar form to a square lattice form known as tubular myelin (TM) (6). In vitro, this transformation is calcium dependent, requiring at least 1-2 mM $(7,8)$. The calcium dependency of TM may be based on one of the major surfactant-associated proteins, SP-A, which is a calcium-binding protein $\left(K_{d}=1-2 \mathrm{mM}\right)$ and which has been shown to aggregate into a multimolecular form in the presence of calcium $(9,10)$. Further, adsorption of the surfactant material in vitro also has a calcium dependency (11-13), and thus the lipid-protein complex in the form of TM has been proposed to be an important intermediate between the secreted material and the functional interfacial form of surfactant $(7,14)$.

We have previously reported that at least part of the calcium necessary for surfactant structure and function in adult rats is delivered to the alveolus with the surfactant components; i.e., in the secreted lamellar bodies (15). It seems likely that lamellar body calcium is a major contributor to the calcium concentrations $(2 \mathrm{mM})$ reported to be in the extremely attenuated alveolar fluid lining layer (hypophase) (16) in the adult. Fetal lung fluid, however, has been reported to contain a calcium concentration incompatible with TM formation (17-19), at a time when rapid adsorption of surfactant components is essential for the successful transition to air breathing. Thus, if indeed calcium is important for surfactant function, and lamellar bodies are the primary source, then lamellar body calcium accumulating mechanisms must have reached maturity before birth. Further, since fetal lungs contain a higher relative alveolar fluid volume than do adult lungs, it seems likely that increased exocytosis of lamellar bodies (20) would be insufficient, and that other pathways of calcium delivery to the alveolus may operate at this critical time. This study demonstrates that the calcium content of individual lamellar bodies is significantly increased just prior to birth, and suggests that this is one of the mechanisms responsible for the necessary elevation of the alveolar fluid calcium concentration.

\section{Methods}

Animals and tissue freezing. Timed-pregnant female Wistar rats were anesthetized with an IP injection of pentobarbital sodium $(50 \mathrm{mg} / \mathrm{kg})$ at 19,20,21, and $22 \mathrm{~d}$ gestation. Three to four fetal animals were rapidly removed from the uterus after laparotomy and hysterotomy, and decapitated. In addition, three to four newborn animals were selected and similarly decapitated; $3-4 \mathrm{~h}, 24 \mathrm{~h}$, and $3 \mathrm{~d}$ after witnessed 
birth. Small $\left(1 \mathrm{~mm}^{3}\right)$ pieces of freshly excised lung tissue were placed on the ends of cleaned $1-\mathrm{cm}$ long applicator sticks and rapidly plunged into liquid nitrogen cooled Freon-22 at $\sim-165^{\circ} \mathrm{C}$. The time from decapitation to freezing was routinely $<90 \mathrm{~s}$. The tissue specimens frozen to the sticks were then stored under liquid nitrogen in a block of frozen Freon-22. "Perinatal" is defined as the entire period from $19 \mathrm{~d}$ gestation to $3 \mathrm{~d}$ after birth. "Prenatal" and "postnatal" are used in their conventional context.

Cryoultramicrotomy and freeze drying. The blocks of Freon-22 were thawed, and the short applicator sticks mounted directly in the chuck of either a modified LKB cryoultramicrotome (LKB Instruments, Inc., Gaithersburg, MD) or a Reichert cryoultramicrotome (Cambridge Instruments, Inc., Monsey, NY), both of which were previously cooled to at least $-100^{\circ} \mathrm{C}$. The specimen was briefly brought to $-90^{\circ} \mathrm{C}$ to allow for evaporation of the Freon, and then returned to $-110^{\circ} \mathrm{C}$ for sectioning. Thin $(100-200 \mathrm{~nm})$ sections were cut with dry glass knives held at $-100^{\circ} \mathrm{C}$, and transferred with bamboo-splinters to 200 mesh copper grids which had been previously coated with a 7-9$\mathrm{nm}$ carbon foil. Similarly prepared grids were inverted and placed on top of the section-laden grids, and the grid "sandwich" was compressed and then isothermically transferred in a heavy brass container to a vacuum apparatus. The grids and container were allowed to passively heat to room temperature under a vacuum of at least $10^{-5}$ torr (usually requiring 12-24 h). After freeze-drying, the grids were lightly carboncoated before storage in a desiccator. Great care was taken to always handle the grids in a dry nitrogen atmosphere after removal from the vacuum device to prevent rehydration. Sections with evidence of rehydration (blurred morphology and loss of sharp ionic gradients across cell membranes) were discarded.

Electron probe microanalysis (EPMA). The unstained freeze-dried cryosections were examined in a Philips 400T TEM (Philips Electronic Instruments, Inc., Mahwah, NJ) equipped with a cryostage (Gatan, Inc., Warrendale, PA) routinely maintained at $-100^{\circ} \mathrm{C}$, a Kevex $\mathrm{Si}(\mathrm{Li})$ $\mathrm{x}$-ray detector, and a multichannel analyzer (Kevex 7000; Kevex Corp., Scotts Valley, CA) interfaced to a VAX 11/750 through a PDP 11/34 computer. Spectra were collected from appropriately sized probe areas of the cryosections. For example, $x$-ray counts from circular to oval spots, $200-500 \mathrm{~nm}$ in diameter, were used to determine lamellar body composition. Several smaller spots $(50-100 \mathrm{~nm})$ in each cell, distributed around organelle-free regions of the cytoplasm, were summed to determine a representative cytoplasmic composition. The stored $\mathrm{x}$-ray spectra were subjected to a computerized routine that identified and quantified peaks by a multiple least-squares fit to reference spectra, and a comparison of characteristic to continuum x-ray peak height in the same spectra. In this way, elemental contents could be normalized to mass in the same region to produce concentration values with units of millimoles per kilogram dry weight, which represent total element, not free, in the probed area. Details and verification of the technique and quantitation routine have been previously published (21). A more recent modification to this routine increases the precision of calcium measurements in high potassium compartments (22) because of the partial overlap of the potassium and calcium $\mathrm{K}$ lines. The minimal detectable calcium concentration measurable with these techniques is between 0.5 and $1.0 \mathrm{mmol} / \mathrm{kg}$ dry wt. For the purposes of this study, concentrations for sodium $(\mathrm{Na})$, magnesium $(\mathrm{Mg})$, phosphorus $(\mathrm{P})$, sulfur $(\mathrm{S})$, chloride $(\mathrm{Cl})$, potassium $(\mathrm{K})$, and calcium (Ca) are determined simultaneously. The purpose for determining and reporting several elements in addition to calcium is to gain insight into the mechanisms of any observed calcium changes, and to assure preparation quality (e.g., sodium/potassium ratios in cytoplasm).

Approximately 10 randomly chosen cells from each of the three to four animals at each of the seven time periods were analyzed; only cells with obvious lamellar bodies were included. From each cell, at least one spectrum was obtained from the cytoplasm, and one each from up to three lamellar bodies. Lamellar bodies were subdivided according to location; intracellular (perinuclear or apical) or extracellular (presumably during or after secretion). Criteria for these positions were relative; cells chosen for analysis had several lamellar bodies in readily apparent different cellular locations; lamellar bodies in questionable cellular positions were not analyzed.

Statistics. Two-way analysis of variance was used to separate the effects of animal variation from that of gestational age or time after birth. Scheffe's test was used to determine the significance of individual means in those variables shown to change by ANOVA. Product moment correlation analysis was used to detect associations between elements in like compartments (within lamellar bodies). Unpaired $t$ test was used only to compare two group means. Significance difference was assumed when the probability of type I error was $<1 \%$.

\section{Results}

Morphology. The freezing methods employed could not prevent the formation of small $(10-100 \mathrm{~nm})$ ice crystals, however, morphology was adequate to identify major intracellular organelles, such as nuclei, mitochondria, lamellar bodies, and in some cases endoplasmic reticulum. Because no cells were found to contain lamellar bodies at $19 \mathrm{~d}$ gestation, type II cells were difficult to identify. Therefore, no data from this point in development will be presented or discussed. At 20,21, and 22 d of gestation, type II cells were easily identified by the presence of lamellar bodies, which were observed in all locations (perinuclear, apical, and exocytotic) even in the 20-d group. The cytoplasm of the fetal cells contained a large amount of granular material which appeared to decrease in volume from 19 to $22 \mathrm{~d}$, and was largely absent in cells from the 1- and 3-d-old newborn animals (Fig. 1, $a-c$ ). Presumably, this material is glycogen, and is consistent with other morphological and biochemical studies of fetal lung (23). Although extracellular lamellar bodies were observed as early as $20 \mathrm{~d}$ of gestation, there was a readily apparent increase in extracellular (alveolar) lipid material after birth, to such a degree that the collapsed alveoli appeared to be filled with lipid (see Fig. $1 d$ ). Further, although morphometric techniques were not employed, the relative number of type II cells appeared to decrease from $20 \mathrm{~d}$ gestation to $3 \mathrm{~d}$ postnatal.

Lamellar body composition. The composition of lamellar bodies across the entire perinatal period is given in Table I. The overall qualitative composition of lamellar bodies in the whole perinatal period is similar to that previously reported for adult lamellar bodies (15). However, several quantitative differences exist. Lamellar body calcium concentrations are significantly increased in the perinatal period (grouped) as compared to the adult $(53 \pm 3$ vs. $37 \pm 2 \mathrm{mmol} / \mathrm{kg}$ dry $\mathrm{wt} \pm \mathrm{SEM}, P$ $<0.01)$. Also, there is a significantly higher lamellar body phosphorus to sulfur ratio in the perinatal period as compared to that in the adult $(22.9$ vs. $12.3 P<0.001)$. This is primarily the result of decreased sulfur concentrations, but there is a slight increase in phosphorus concentrations, especially in the prenatal lamellar bodies. The previously observed relative excess of chloride in adult lamellar bodies was also observed in perinatal lamellar bodies, indicated by comparison of potassium/chloride ratios of lamellar body and cytoplasm. Further, unlike lamellar bodies in adult type II cells, perinatal lamellar bodies appear to have a relative excess of sodium, as indicated by significant differences of sodium/chloride and sodium/potassium ratios in lamellar bodies versus cytoplasm at the same time points.

In addition to differences between perinatal lamellar bodies and those of the adult, there were significant changes in lamellar body elemental composition within the perinatal pe- 

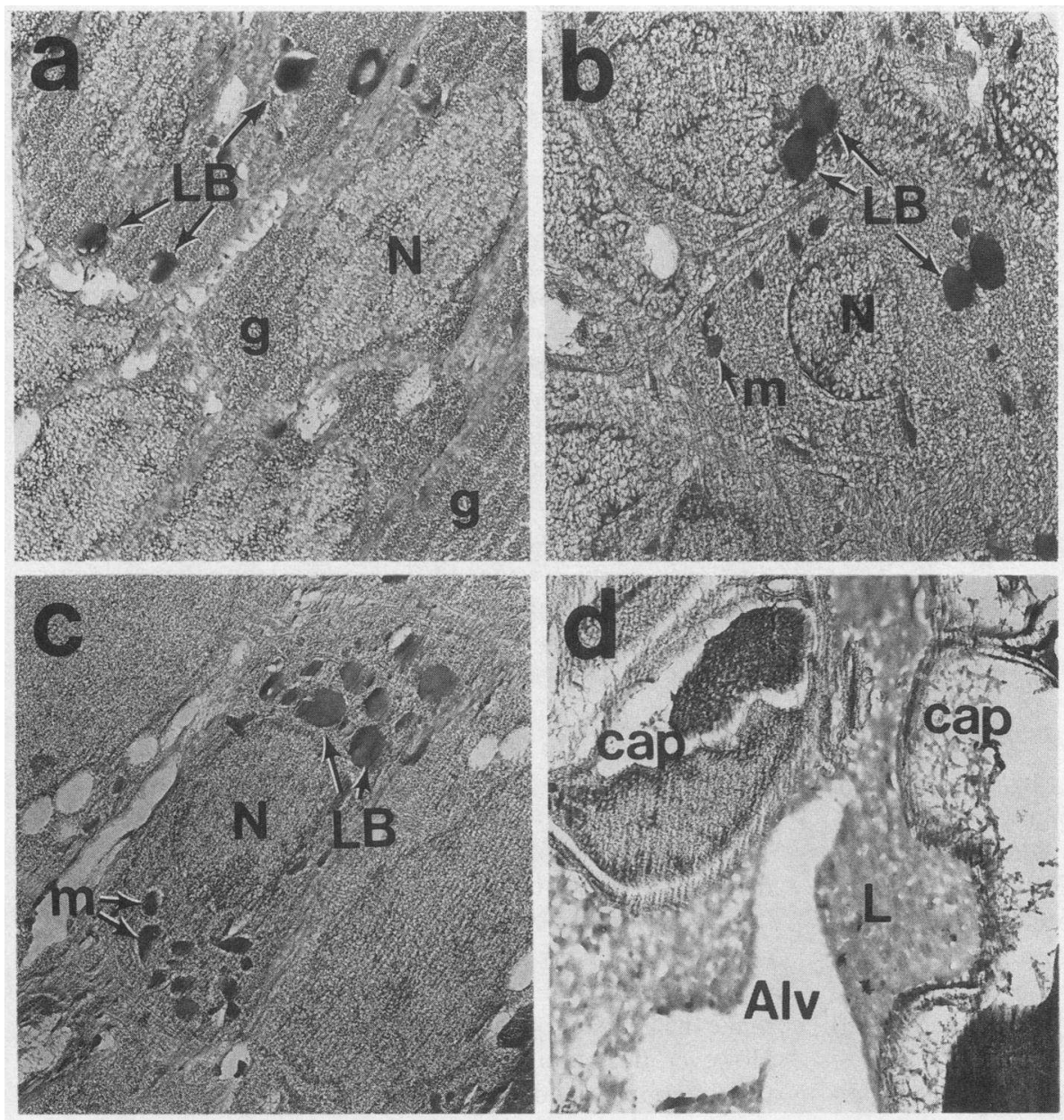

Figure 1. Electron micrographs of unstained, unembedded freeze-dried cryosections (all at $\times 5,600$ ) of fetal and neonatal rat lung. (a) 20 day gestation, (b) 22 day gestation, $(c)$ and $(d) 1 \mathrm{~d}$ post-natal. $N$, nucleus, $L B$, lamellar body, $m$, mitochondria, $g$, glycogen, cap, pulmonary capillary (each containing an RBC), $A l v$, alveolar space, $L$, lipid material in alveolus. riod. Lamellar body phosphorus, calcium, and magnesium concentrations all rise during the prenatal period to peaks at 22 d (term) and then decline to approximately adult values shortly (hours) after birth. Lamellar body sulfur increases slightly over the whole perinatal time period with no change seen at birth. The other elements examined showed no consistent change over the studied perinatal period.
A significant difference in elemental concentrations between lamellar bodies in a perinuclear position compared with those in an apical position, as well as between the intracellular and extracellular positions was consistently observed (Table II). Apical lamellar body calcium and chloride concentrations were significantly elevated as compared with those lamellar bodies in a perinuclear position. These apical increases were

Table I. Composition of All Intracellular Lamellar Bodies by Age

\begin{tabular}{|c|c|c|c|c|c|c|c|}
\hline \multirow[b]{2}{*}{ Element } & \multicolumn{3}{|c|}{ Prenatal } & \multicolumn{4}{|c|}{ Postnatal } \\
\hline & $20 d$ & $21 \mathrm{~d}$ & $22 \mathrm{~d}$ & $3-5 h$ & $1 \mathrm{~d}$ & $3 \mathrm{~d}$ & Adult* \\
\hline & \multicolumn{3}{|c|}{$\mathrm{mmol} / \mathrm{kg} d r y \mathrm{w} t$} & \multicolumn{4}{|c|}{$\mathrm{mmol} / \mathrm{kg} d r y \mathrm{wt}$} \\
\hline $\mathrm{Ca}$ & $56 \pm 4$ & $62 \pm 4^{\ddagger}$ & $70 \pm 4^{\ddagger}$ & $32 \pm 2$ & $49 \pm 3$ & $48 \pm 4$ & $37 \pm 2$ \\
\hline $\mathbf{M g}$ & $7 \pm 1$ & $11 \pm 1$ & $13 \pm 1^{\ddagger}$ & $9 \pm 1$ & $8 \pm 1$ & $9 \pm 1$ & $8 \pm 1$ \\
\hline $\mathbf{P}$ & $1,180 \pm 14$ & $1,260 \pm 16^{\ddagger}$ & $1,300 \pm 24^{\ddagger}$ & $1,150 \pm 14$ & $1,160 \pm 16$ & $1,110 \pm 15$ & $1,130 \pm 24$ \\
\hline $\mathbf{S}$ & $40 \pm 2$ & $70 \pm 4^{\ddagger}$ & $46 \pm 2$ & $52 \pm 3$ & $55 \pm 3$ & $56 \pm 3$ & $92 \pm 4$ \\
\hline $\mathrm{Na}$ & $50 \pm 4$ & $64 \pm 6$ & $80 \pm 5$ & $83 \pm 5$ & $62 \pm 4$ & $69 \pm 7$ & $54 \pm 4$ \\
\hline $\mathrm{Cl}$ & $63 \pm 5$ & $80 \pm 6$ & $69 \pm 7$ & $73 \pm 5$ & $70 \pm 5$ & $84 \pm 7$ & $81 \pm 4$ \\
\hline $\mathbf{K}$ & $66 \pm 4$ & $90 \pm 4$ & $70 \pm 4$ & $103 \pm 4$ & $91 \pm 4$ & $92 \pm 4$ & $122 \pm 4$ \\
\hline \multicolumn{8}{|c|}{ Lamellar bodies/cells } \\
\hline$(n)$ & $51 / 27$ & $59 / 32$ & $59 / 32$ & $56 / 39$ & $60 / 34$ & $51 / 30$ & $91 / 30$ \\
\hline Animals (n) & 3 & 3 & 3 & 4 & 3 & 3 & 7 \\
\hline
\end{tabular}

Values are given as mean \pm SEM. * Adult values from Reference $15 . \quad{ }^{\ddagger} P \leq 0.01$ by ANOVA and Scheffe. 
Table II. Prenatal Lamellar Body Composition by Cellular Position

\begin{tabular}{lccc}
\hline & \multicolumn{2}{c}{ Position } \\
\cline { 2 - 3 } \multicolumn{1}{c}{ Element } & Perinuclear & Apical & Extracellular \\
\hline & & $m m o l / k g d r y w t$ \\
$\mathrm{Ca}$ & $52 \pm 3$ & $76 \pm 4^{*}$ & $38 \pm 2^{*}$ \\
$\mathrm{Mg}$ & $10 \pm 1$ & $11 \pm 1$ & $8 \pm 2$ \\
$\mathrm{P}$ & $1,240 \pm 15$ & $1,270 \pm 18$ & $1,150 \pm 23^{*}$ \\
$\mathrm{~S}$ & $56 \pm 3$ & $48 \pm 2$ & $60 \pm 5$ \\
$\mathrm{Na}$ & $62 \pm 4$ & $70 \pm 5$ & $510 \pm 40^{*}$ \\
$\mathrm{Cl}$ & $57 \pm 4$ & $87 \pm 6^{*}$ & $360 \pm 27^{*}$ \\
$\mathrm{~K}$ & $81 \pm 3$ & $70 \pm 4$ & $86 \pm 7$ \\
& & & 31 \\
Lamellar bodies $(n)$ & 93 & 76 & 9 \\
Animals $(n)$ & 9 & 9 & \\
\hline
\end{tabular}

Values are given as mean \pm SEM.

* $P \leq 0.01$ compared to perinuclear by ANOVA and Scheffe's.

not explained solely by proximity to the extracellular space coupled with slight translocation of these highly diffusible elements during preparation for EPMA, since there was no significant increase in sodium content in the apical as compared to the perinuclear lamellar bodies. Not unexpectedly, extracellular lamellar bodies showed a significantly elevated sodium and chloride content, and significantly reduced magnesium, phosphorus, and calcium concentrations as compared to all (grouped) intracellular lamellar bodies.

Cytoplasmic composition. Type II cell cytoplasmic composition is shown in Table III, and is qualitatively similar to that observed in the adult. However, there was a significant increase in phosphorus, sulfur, and calcium concentration over the time period studied. Cytoplasmic phosphorus content increased dramatically immediately after birth, and then leveled off, whereas both sulfur and calcium increased gradually throughout the perinatal period to the adult values. No significant change in the other elements occurred over the time period studied, although if the entire perinatal period is grouped and compared to the adult, a significantly higher chloride concentration exists in type II cell cytoplasm during the perinatal period $(240 \pm 14$ vs. $158 \pm 7 \mathrm{mmol} / \mathrm{kg}$ dry $w t \pm S E M, P$ $<0.01$ ).

\section{Discussion}

Calcium and surfactant function. Calcium ion appears to be involved in at least two, probably separate, processes in surfactant function. First, millimolar calcium is required for the formation of tubular myelin $(7,8)$, a transformation probably also requiring the presence of a surfactant-associated protein (SP-A), which has recently been shown to undergo a calciumdependent aggregation $\left(K_{d}=1 \mathrm{mM}\right)(9,10)$. Tubular myelin is thought to be a form of surfactant that is intermediate between the lamellar bodies and the presumably functional form, the interfacial monolayer $(6,8,14)$. Second, it has been shown that, even in the absence of the protein component, calcium increases the rate of adsorption of phospholipids to an interface (11-13), which is probably due to reduction of electrostatic interactions between the zwitterionic and anionic phospholipids. Thus, it is especially surprising that, at a time when rapid adsorption to the air-liquid interface is essential for survival, i.e., at birth, the only measurements of lung fluid calcium concentration report it to be around 0.5 millimolar (17, 18). If calcium is indeed important for surfactant function, mechanisms must be in place for rapid elevation of the lung fluid calcium concentration perinatally. Measurements of adult lamellar body calcium content in situ (15), coupled with the large perinatal "burst" of lamellar body secretion (20), make the lamellar body a likely source of the required calcium. However, this requires that mature calcium transporting function in lamellar bodies be reached prenatally, a situation that, at least in the case of another calcium-transporting organelle, sarcoplasmic reticulum, has not been found to be true (24). Further, the large relative fluid volume of fetal lung at birth requires that calcium delivery to the alveolus be larger than in the adult. Although this requirement may be partially met by the burst of secretion mentioned above, the results of this study clearly show that lamellar body calcium content is substantially increased in this period. This finding suggests that mature calcium transport function in lamellar bodies is achieved before birth, and further, is consistent with the no-

Table III. Type II Cell Cytoplasmic Composition by Age

\begin{tabular}{|c|c|c|c|c|c|c|}
\hline \multirow[b]{2}{*}{ Element } & \multicolumn{3}{|c|}{ Prenatal } & \multicolumn{3}{|c|}{ Postnatal } \\
\hline & $20 \mathrm{~d}$ & $21 \mathrm{~d}$ & $22 \mathrm{~d}$ & $3-5 \mathrm{~h}$ & $1 \mathrm{~d}$ & $3 \mathrm{~d}$ \\
\hline & \multicolumn{3}{|c|}{$\mathrm{mmol} / \mathrm{kg} d r y w t$} & \multicolumn{3}{|c|}{$\mathrm{mmol} / \mathrm{kg} d r y \mathrm{wt}$} \\
\hline $\mathrm{Ca}$ & $2.6 \pm 0.7$ & $3.6 \pm 0.7$ & $3.8 \pm 0.6$ & $4.3 \pm 0.6$ & $4.9 \pm 0.8$ & $6.9 \pm 1.1^{*}$ \\
\hline Mg & $38 \pm 2$ & $52 \pm 2$ & $52 \pm 2$ & $62 \pm 3^{*}$ & $53 \pm 2$ & $50 \pm 2$ \\
\hline $\mathbf{P}$ & $360 \pm 19$ & $491 \pm 31$ & $465 \pm 28$ & $747 \pm 24^{*}$ & $712 \pm 27^{*}$ & $608 \pm 20$ \\
\hline $\mathbf{S}$ & $146 \pm 7$ & $183 \pm 9$ & $216 \pm 12$ & $226 \pm 6$ & $267 \pm 9^{*}$ & $235 \pm 9$ \\
\hline $\mathrm{Na}$ & $135 \pm 12$ & $155 \pm 12$ & $140 \pm 10$ & $221 \pm 16$ & $138 \pm 15$ & $166 \pm 18$ \\
\hline $\mathrm{Cl}$ & $297 \pm 23$ & $283 \pm 12$ & $259 \pm 10$ & $254 \pm 10$ & $212 \pm 10$ & $186 \pm 7^{*}$ \\
\hline $\mathbf{K}$ & $694 \pm 28$ & $732 \pm 17$ & $725 \pm 16$ & $651 \pm 18$ & $649 \pm 24$ & $535 \pm 18$ \\
\hline Cells $(n)$ & 27 & 32 & 32 & 39 & 34 & 30 \\
\hline Animals $(n)$ & 3 & 3 & 3 & 4 & 3 & 3 \\
\hline
\end{tabular}

Values are given as mean \pm SEM. Differences from adult values discussed in the text. ${ }^{*} P \leq 0.01$ by ANOVA and Scheffe's. 
tion that calcium is important for in vivo surfactant function. That lamellar body-derived calcium is sufficient to raise hypophase free calcium concentration is suggested by comparison of extracellular to intracellular lamellar body calcium content (Table II). Since lamellar bodies appear to lose $\sim 35 \mathrm{mmol} / \mathrm{kg}$ dry wt after exocytosis, and since the ratio of alveolar hypophase to surfactant ( $w t / w t)$ is $\sim 0.3$, sufficient calcium to raise hypophase free calcium by the required 1-2 mmol/liter is clearly available, and is the probable explanation for the recently reported rapid rise in neonatal lamb alveolar hypophase calcium concentration within minutes after birth (25).

Thus, if the role of the observed elevation of lamellar body calcium content is to rapidly raise the alveolar liquid calcium concentration to promote normal surfactant function, then it is likely that premature infants at risk for respiratory distress syndrome (RDS) have both a deficiency of surfactant components (phospholipids and proteins), as well as a low alveolar liquid calcium concentration. Thus it seems that surfactant preparations (artificial or natural) to be used for exogenous therapy of RDS should be delivered in a calcium-containing solution (26), instead of the normal saline vehicle commonly used (2).

Evidence for active calcium transport by lamellar bodies. These measurements of lamellar body calcium content reflect total concentration and not that which is free. Consideration of the calcium binding character of lamellar body contents, together with their low water content (15-20\%), suggests that lamellar body free calcium concentration is similar to extracellular fluid. Two observations have confirmed this hypothesis. Assuming that freshly exocytosed lamellar bodies (lacking a limiting membrane) rapidly reach equilibrium with the ionic composition of the media, determination of calcium content in these lamellar bodies with EPMA can be used as an indicator of the ambient free calcium concentration. Thus, perinatal lamellar bodies in an extracellular position (free calcium $\sim 0.2-0.7 \mathrm{mM}$ ) were found to contain less than half of the calcium found in the intracellular lamellar bodies. Further, this exocytotic lamellar body calcium content is significantly less ( 35 vs. $49 \mathrm{mmol} / \mathrm{kg}$ dry wt, $P<0.001$ ) than that found in similarly located lamellar bodies in the adult, consistent with the higher free calcium concentration measured in the (rabbit) adult $(\sim 2 \mathrm{mM})(16)$. Also, the calcium content of extracellular lamellar bodies in explanted adult lung tissue incubated in $30 \mu \mathrm{M}$ calcium (unpublished observations) was significantly lower ( $5 \mathrm{mmol} / \mathrm{kg}$ dry wt) than the fetal (this study) or the in situ adult exocytotic lamellar bodies (15). Thus, the evidence derived from these EPMA measurements indicates that lamellar body free calcium is substantially higher than cytoplasmic, implying the existence of an active transport system.

Further evidence in support of active transport in these type II cell organelles comes from an analysis of lamellar body composition by intracellular position. Table II clearly shows a significant increase in both calcium and chloride (see below) content in those lamellar bodies located apically as compared to those in a perinuclear position, and this relationship is true at each time point studied. The apical increase in calcium concentration most likely represents continued activity of transport systems during maturation of the secretory granule. A time dependency of calcium uptake may also be responsible for the large fall in lamellar body calcium content observed in the first few hours after birth, during which time the type II cell is maximally stimulated and surfactant secretion has increased severalfold over the prenatal period (20). Taken together, the above in situ evidence strongly suggests that calcium is translocated into the lamellar body in an active fashion.

Potential mechanisms of lamellar body calcium transport. The mechanisms or character of calcium transport in these organelles is unknown. In fact, in other secretory organelles found to have a high calcium content, the mechanisms are similarly not known. For example, efforts to find a calcium ATPase in chromaffin granule limiting membrane have been largely unsuccessful (27). Because of the acid interior of chromaffin granules (and other secretory granules), proton/calcium antiport activity was sought, but could not be demonstrated (28). These latter investigators suggested that calcium accumulation was due to sodium/calcium exchange, but more recent studies using EPMA of in situ chromaffin granules failed to show the existence of the necessary sodium gradient (29). This study provides no direct evidence for any of these possible mechanisms, but some observations are relevant. First, by comparing ratios of sodium to potassium, sodium to chloride and potassium to chloride in the lamellar body with that in the cytoplasm, it is apparent that there is a relative excess of both sodium and chloride in lamellar bodies. Thus, the sodium gradient necessary for sodium/calcium exchange may be present in in situ lamellar bodies, at least in the fetus. Also, the chloride gradient probably represents a passive chloride conductance in parallel with the known lamellar body electrogenic proton ATP-ase $(30,31)$. Further, since EPMA provides data on individual organelles, and since there is some variability between the organelles both within and between conditions, it is possible to examine the data for correlations between elements in the same compartment. For example, if sodium/calcium exchange accounted for calcium accumulation, one might expect a significant positive correlation to exist between the two elements in lamellar bodies. The results of such a correlation analysis is shown in Table IV, which demonstrates no significant correlation of calcium with sodium. There is, however, a highly significant correlation of calcium with chloride. Further, as stated above, there is a significant increase in lamellar body chloride content (but not sodium) in apical as compared to perinuclear positions. This suggests that factors responsible for distribution of chloride, such as $\mathrm{pH}$, may also be responsible for calcium accumulation. Although this evidence is consistent with a proton/calcium antiport, verification will await studies using appropriate maneuvers in isolated tissue, cells or organelles.

Lamellar body phosphorus and sulfur. Based on the known phospholipid content of lamellar bodies (1), there is excess phosphorus in prenatal intracellular lamellar bodies. Pure surfactant phospholipids should have a phosphorus content of no

Table IV. Correlation Analysis (Pearson's $r$ ) of All Intracellular Prenatal Lamellar Bodies $(n=169)$

\begin{tabular}{lllll}
\hline Elements & $\mathrm{Na}$ & $\mathrm{Mg}$ & $\mathrm{P}$ & $\mathrm{Cl}$ \\
\hline $\mathrm{Mg}$ & 0.22 & & & \\
$\mathrm{P}$ & 0.15 & $0.33^{*}$ & & \\
$\mathrm{Cl}$ & $0.58^{*}$ & 0.02 & -0.06 & \\
$\mathrm{Ca}$ & 0.12 & 0.15 & 0.24 & $0.58^{*}$ \\
\hline
\end{tabular}

$* P \leq 0.01$. 
more than $\sim 1,350 \mathrm{mmol} / \mathrm{kg}$ dry $\mathrm{wt}$, and this has been confirmed with EPMA of pure phosphatidylcholine (15). Since lamellar bodies contain only about $80 \%$ phospholipid, even in the prenatal period $(1,32,33)$, phosphorus concentration should be no more than about $1,100 \mathrm{mmol} / \mathrm{kg}$ dry wt, which is what is found in adult in situ lamellar bodies, and also those in the neonate (this study). Because of a recent finding of ATP in adult rat lung lavage fluid (34), it is possible that the excess phosphorus is due to ATP accumulation. Although ATP is known to be accumulated in other secretory granules (35), this would represent a novel positive feedback system in the lung since ATP is known to be a potent secretagogue for surfactant secretion both in vivo and in isolated cells (36). Also consistent with the presence of ATP in lamellar body are the borderline significant changes in magnesium content prenatally, and the significant correlation of phosphorus and magnesium in all prenatal intracellular lamellar bodies (Table IV). An alternative explanation for this significant increase in lamellar body phosphorus in the prenatal period would be a major shift in the phospholipid class, a possibility which has not been supported by biochemical approaches (32). Lamellar body sulfur does not appear to change in the perinatal period, but it is significantly reduced from what is found in adult lamellar bodies ( 54 vs. $84 \mathrm{mmol} / \mathrm{kg}$ dry wt, $P<0.001$ ). This may reflect a lower relative production of the surfactant-associated proteins, which probably account for the majority of lamellar body sulfur. Alternatively, a difference in posttranslational modification of surfactant proteins, which may include sulfation (37), could explain the lower sulfur content of lamellar bodies in the perinatal period.

Cytoplasmic composition. Of interest was the slow, consistent, and significant increase in cytoplasmic calcium content over the studied perinatal period. The calcium content (total) of adult type II cell cytoplasm reported previously (15) was elevated over what is found in the cytoplasm of muscle cells (38), but consistent with what is found in the cytoplasm of other secretory cells when using EPMA of freeze-dried cryosections $(39,40)$. The relatively high total calcium content of the cytoplasm in these secretory cells has been attributed to the densely distributed endoplasmic reticulum (ER), which is generally not visualized in cryosections, and which is known to accumulate and release calcium in a fashion similar to SR (39, 41). Thus, the increase in "cytoplasmic" calcium content in this perinatal period probably reflects either an increased density/volume of the ER, an increase in ER calcium binding capacity or an increased activity of the ER calcium transporting system. Distinction between these possibilities is not possible with the data derived from this study.

Type II cell sodium and potassium contents and ratios indicate that these cells are maintaining normal ion gradients at the time of freezing, and that the preparation used preserved these gradients until the time of analysis. Sodium/potassium ratios are essentially the same as observed in the adult. An excess of chloride was consistently observed in the cytoplasm of these perinatal type II cells, which appeared to drop beginning at $22 \mathrm{~d}$ of gestation, and essentially at adult levels by the third postnatal day. The meaning of these chloride changes are not clear. It is known that type II cells are involved in active chloride transport, into the alveolar fluid prenatally, and then reversing direction at term $(17,18,42)$. Thus it is conceivable that the gradual reduction in cytoplasmic chloride content reflects activation of basolateral chloride transport as the fetus nears term. In addition, since chloride ion has been shown to increase the acidification rate of multivesicular bodies (43), it is possible that a similar effect on fetal lamellar bodies sets the stage for the upcoming perinatal burst of secretion. Further, if proton/calcium exchange is a mechanism of calcium uptake by lamellar bodies, then an increase in acidification may explain, in part, the elevated calcium content of fetal as compared to adult lamellar bodies.

The significant increase in cytoplasmic phosphorus and sulfur content immediately after birth likely reflects an increase in production of the secretory products of this cell, which include both protein and phospholipid. The abruptness of this increase after birth is consistent with the notion of reuptake and recycling of surfactant components (44), whose contribution to overall surfactant production by the type II cell is believed to increase dramatically immediately after birth (20).

\section{Acknowledgments}

The author expresses sincere thanks to Andrew and Avril Somlyo for their support, advice and the generous provision of equipment, to Aron Fisher for advice and reviewing this manuscript, to John Silcox for expert technical assistance, and to Maryellen Eckenhoff for figure preparation.

This work was supported by an American Lung Association Research grant.

\section{References}

1. Van Golde, L. M. G., J. J. Batenburg, and B. Robertson. 1988. The pulmonary surfactant system: biochemical aspects and functional significance. Physiol. Rev. 68:374-455.

2. Jobe, A., and M. Ikegami. 1987. Surfactant for the treatment of respiratory distress syndrome. Am. Rev. Respir. Dis. 136:1256-1275.

3. Harris, J., F. Jackson, M. Moxley, and W. J. Longmore. 1988. Dysfunction of the surfactant system in the adult respiratory distress syndrome. Am. Rev. Respir. Dis. 137:279A.

4. Coultas, P. G., R. G. Ahier, and R. L. Anderson. 1987. Altered turnover and synthesis rates of lung surfactant following thoracic radiation. J. Rad. Oncol. Biol. Phys. 13:233-237.

5. Sano, K., D. R. Voelker, and R. J. Mason. 1987. Effect of secretagogues on cytoplasmic free calcium in alveolar type II epithelial cells. Am. J. Physiol. 253:C679-C686.

6. Williams, M. C. 1977. Conversion of lamellar body membranes into tubular myelin in alveoli of fetal rat lungs. J. Cell Biol. 72:260277.

7. Benson, B. J., M. C. Williams, K. Sueishi, J. Goerke, and T. Sargeant. 1984. Role of calcium ions in the structure and function of pulmonary surfactant. Biochim. Biophys. Acta. 793:18-27.

8. Sanders, R. L., R. J. Hassett, and A. E. Vatter. 1980. Isolation of lung lamellar bodies and their conversion to tubular myelin in vitro. Anat. Rec. 198:485-501.

9. Haagsman, H. P., S. Hawgood, and B. J. Benson. 1987. The major lung surfactant protein, SP 28-36, is a calcium-dependent, carbohydrate-binding protein. J. Biol. Chem. 262:13877-13880.

10. Haagsman, H. P., and S. Hawgood. 1987. $\mathrm{Ca}^{2+}$-dependent self association of SP-A, the major lung surfactant protein. Fed. Proc. 2:A1044.

11. Davies, R. J., M. Genghini, D. V. Walters, and C. J. Morley. 1986. The behaviour of lung surfactant in electrolyte solutions. Biochim. Biophys. Acta. 878:135-145.

12. Kobayashi, T., and B. Robertson. 1983. Surface adsorption of pulmonary surfactant in relation to bulk-phase concentration and presence of $\mathrm{CaCl}$. Respiration 44:63-70. 
13. Weber, M. J., and F. Possmayer. 1984. Calcium interactions in pulmonary surfactant. Biochim. Biophys. Acta. 796:83-91.

14. Power, J. H. T., H. A. Barr, M. E. Jones, and T. E. Nicholas. 1987. Changes in surfactant pools after a physiologic increase in alveolar surfactant. J. Appl. Physiol. 63:1902-1911.

15. Eckenhoff, R. G., and A. P. Somlyo. 1988. Rat lung type II cell and lamellar body: elemental composition in situ. Am. J. Physiol. 254:C614-C620.

16. Neilson, D. W. 1986. Electrolyte composition of pulmonary alveolar subphase in anesthetized rabbits. J. Appl. Physiol. 60:972979.

17. Nielson, D. W. 1988. Changes in the pulmonary alveolar subphase at birth in term and premature lambs. Pediatr. Res. 23:418-422.

18. Adamson, T. M., R. D. H. Boyd, H. S. Platt, and L. B. Strang. 1969. Composition of alveolar liquid in the foetal lamb. J. Physiol. 204:159-168

19. Stevens, P. A., J. R. Wright, and J. Clements. 1987. Changes in quantity, composition, and surface activity of alveolar surfactant at birth. J. Appl. Physiol. 63:1049-1057.

20. Jacobs, H., A. Jobe, M. Ikegami, and S. Jones. 1982. Surfactant phosphatidylcholine source, fluxes, and turnover times in 3-day-old, 10-day-old, and adult rabbits. J. Biol. Chem. 257:1805-1810.

21. Shuman, H., A. V. Somlyo, and A. P. Somlyo. 1976. Quantitative electron probe microanalysis of biological thin sections: methods and validity. Ultramicroscopy. 1:317-339.

22. Kitazawa, T. H., H. Shuman, and A. P. Somlyo. 1983. Quantitative electron probe analysis: problems and solutions. Ultramicroscopy. 11:251-262.

23. Carlson, K. S., P. Davies, B. T. Smith, and M. Post. 1987. Temporal linkage of glycogen and saturated phosphatidylcholine in fetal lung type II cells. Pediatr. Res. 22:79-82.

24. Leberer, E., K. T. Hartner, and D. Pette. 1988. Postnatal development of $\mathrm{Ca}^{2+}$-sequestration by the sarcoplasmic reticulum of fast and slow muscles in normal and dystrophic mice. Eur. J. Biochem. 174:247-253.

25. Nielson, D. W., and M. B. Lewis. 1988. Calcium increases in pulmonary alveolar fluid in lambs at birth. Pediatr. Res. 24:322-325.

26. Enhorning, G., A. Shennan, F. Possmayer, M. Dunn, C. P. Chen and J. Milligan. 1985. Prevention of neonatal respiratory distress syndrome by tracheal instillation of surfactant: a randomized clinical trial. Pediatrics. 76:145-153.

27. Winkler, H. 1976. The composition of adrenal chromaffin granules: an assessment of controversial results. Neuroscience. 9:917924.

28. Yoon, P. S., and R. R. Sharp. 1985. Ca and proton transport in chromaffin granule membranes: a proton NMR study. Biochemistry 24:7269-7273.

29. Ornberg, R. L., G. A. J. Kuijpers, and R. D. Leapman. 1988 Electron probe microanalysis of the subcellular compartments of bovine adrenal chromaffin cells. J. Biol. Chem. 263:1488-1493.
30. Glickman, J. K., K. Croen, S. Kelly, and Q. Al-Awqati. 1983. Golgi membranes contain and electrogenic $\mathrm{H}+$ pump in parallel to a chloride conductance. J. Cell Biol. 97:1303-1308.

31. Gupta, R. P., and T. A. Venkitasubramanian. 1983. (Ca or Mg) ATPase in lung lamellar bodies. Ind. J. Biochem. Biophys. 20:381385.

32. Egberts, J., G. C. M. Gorree, and A. A. H. Boonman. 1986. Lack of change in the composition of fetal lamb lung surfactant during gestation. Biochim. Biophys. Acta. 878:146-151.

33. Spain C. L., R. Silbajoris, and S. L. Young. 1987. Alterations of surfactant pools in fetal and newborn rat lungs. Pediatr. Res. 21:5-9.

34. Rice, W. R., and J. R. Wispe. 1988. Quantitative changes in airway ATP levels during oxygen injury. Am. Rev. Respir. Dis. 137:76A.

35. Weber, A., E. A. Westhead, and H. Winkler. 1983. Specificity and properties of the nucleotide carrier in chromaffin granules from bovine adrenal medula. Biochem. J. 210:789-794.

36. Rooney, S. A., and L. I. Gobran. 1988. Adenosine and leukotrienes have a regulatory role in lung surfactant secretion in the newborn rabbit. Biochim. Biophys. Acta. 960:98-106.

37. Weaver, T. E., K. L. Kropp, and J. A. Whitsett. 1987. In vitro sulfation of pulmonary surfactant-associated protein-35. Biochim. Biophys. Acta. 914:205-211.

38. Somlyo, A. P., and A. V. Somlyo. 1986. Electron probe analysis of calcium content and movements in sarcoplasmic reticulum, endoplasmic reticulum, mitochondria, and cytoplasm. J. Cardiovasc. Pharmacol. 8:S42-S47.

39. Izutsu, K. T., and D. E. Johnson. 1986. Changes in elemental concentrations of rat parotid acinar cells following pilocarpine stimulation. J. Physiol. 381:297-309.

40. Howell, S. L., W. Montague, and M. Tyhurst. 1975. Calcium distribution in islets of langerhans: a study of calcium concentration and of calcium accumulation in B-cell organelles. J. Cell Sci. 19:395409 .

41. Bond, M., G. Vadasz, A. V. Somlyo, and A. P. Somlyo. 1987. Subcellular calcium and magnesium mobilization in rat liver stimulated in vivo with vasopressin and glucagon. J. Biol. Chem. 262:15630-15636.

42. Kitterman, J. A., P. L. Ballard, J. A. Clements, E. J. Mescher, and W. H. Tooley. 1979. Tracheal fluid in fetal lambs: spontaneous decrease prior to birth. J. Appl. Physiol. 47:985-989.

43. Van Dyke, R. 1988. Proton pump-generated electrochemical gradients in rat liver multivesicular bodies: quantitation and effects of chloride. J. Biol. Chem. 263:2603-2611.

44. Chander, A., J. Reicherter, and A. Fisher. 1987. Degradation of dipalmitoyl phosphatidylcholine by isolated rat granular pneumocytes and reutilization for surfactant synthesis. J. Clin. Invest. 79:11331138. 